\title{
Causes of food safety problems in China and some countermeasures
}

\author{
Pingfang Yang \\ International Business School, \\ Yunnan University of Finance and Economics, \\ Kunming, China \\ 93039219@qq.com
}

\begin{abstract}
First, we review the literatures about food safety research. Second, we analyze food safety problems in China and their causes. Finally, the author proposes some suggestions to solve these problems, such as strengthening the supervision of related departments and their coordination, perfecting the system of laws and technical standards, speeding up the construction of credit system of food safety, and establishing and perfecting the mechanism of punishing dishonesty behaviors.
\end{abstract}

Keywords -food safety; credit system; government regulation; supervision

\section{INTRODUCTION}

In Food Safety Law of People's Republic of China issued in 2009 , food safety refers that the food is non-toxic, harmless, and conforming to proper nutritive requirements, and does not cause any acute, sub-acute or chronic hazards to human health.

Access to sufficient safe food is a basic requirement for human health. Food safety has emerged as an important global issue with international trade and public health implications. In recent years, there has been increasing public concern for food safety in China, and media attention to food safety issues has been increasing. On April 7, 2015(the World Health Day), the World Health Organization (WHO) chose to focus on food safety. All governments have strived consistently to increase traceability and transparency through integrated approaches to food safety management. As a result of these developments, there has been a general reform of existing frameworks for the governance of food safety globally [7].

Chinese president Xi Jinping used "two issues" to illustrate the importance of the problem of food safety, i.e., it is not only an important livelihood issue, but also an important political issue. In May 2015, he stressed to strengthen food and drug safety supervision, speed up the construction of scientific and perfect system about the governance of food and drug by means of the most serious standards, the strictest supervision, the most severe punishment, and the most serious accountability. Since the Eighteenth National Congress of the CPC, leaders of the central committee of the CPC have attached great importance to food safety problems, and advocated to use heavy regulations to ensure the safety on the tip of the tongue. In 13th Five-Year Planning proposals, the problem of food safety is raised to the top of national strategy.
It is required to implement food safety strategy, and form a system of food safety governance which is strict and efficient, and with the feature of society multi-governance, so as to make people eat at ease.

Many researchers have studied food safety issues and the approaches of ensuring food safety.

L. Manning et al. identify the issues for an organization if their management system is focused primarily on minimizing quality costs rather than producing safe, wholesome food [10]. David L. Ortega et al. explore Chinese food safety issues by analyzing select incidents within the Chinese agricultural marketing system. A marketing utility framework is utilized to discuss some of the major food safety incidents in China and potential solutions are explored [4]

Ruth M.W. Yeung et al. draws on a review of research literature to develop a conceptual framework to identify and review the factors influencing consumer perception of food safety related risks and the likely impact on purchasing behavior [14]. Sinne Smed et al. analyze how news about food-related health risks affects consumers' demands for safe food products. Negative safety news about one product variety can provide significant stimulation to the demand for safe varieties [15]. Christopher J. Griffith reviews the history of food safety and presents a model for studying food safety [3].

Annabelle M. Wilson et al. report how food regulators communicate with consumers about food safety and how they believe consumers understand their role in relation to food safety. They found that food regulators have a key role in communicating information to consumers about food safety and food incidents [1].

Imca Sampers et al. gave an insight in the performance of Hazard Analysis and Critical Control Point (HACCP)-based food safety management systems (FSMS) implemented in Japanese milk processing plants. The results revealed that the microbial food safety output was higher for companies with national HACCP approval [5]. Photis Papademas et al. review the food safety management systems as well as the relevant EC Regulations that are currently implemented by the dairy industry [13]. A food safety performance diagnosis, based on seven indicators and corresponding assessment grids have been developed by L. Jacxsens et al. and validated in nine European food businesses [9]. Zhelyu Vladimirov analyzed 
the factors for the implementation of the efficient food quality and safety management system in the food industry and the food retail sector in Bulgaria [20]. Nada Smigic et al. analyze the current situation of multidimensional food safety assurance in Serbia [11].

Liu and Zhang argued that China's food safety regulatory system has experienced three stages since 1992: multi-level management, semi-vertical management and mixed management dominated by local management. The transformation of the three stages is tightly connected with the regulation and reform of China's central local government relationship undergone since 1990s. The author found out the deficiency of current mixed management system and therefore "regulatory federalism" should be employed, establishing a more scientific and effective regulatory regime and fostering a collaborative regulatory system between the central-local government [8].

Chen et al. provided suggestions for the system of food safety supervision and management by field investigation and analysis on the food safety supervision and management departments in Shanghai Municipality, Sichuan and Gansu Provinces and their current supervisory situation [2]. Yang and $\mathrm{Wu}$ compared domestic and international food safety supervision mechanism, analyzed existing problems in food safety supervision, and pointed out the highlights of international food safety supervision mechanism [17]. Zhang et al. establish an evolutionary game model and analyze the mechanism where third party supervision influences the behavior of food enterprises and government supervision departments. It is found that to some extent the third-party intendance can replace the supervisory role of government supervision departments [18].

Zhao suggests leveraging "Internet plus" way of thinking and technical means and making use of information platform, to accelerate the construction of electronic supervision system for food safety, strengthen the food safety traceability management and whole process supervision, and establish an integrated social supervision system combining government regulation and public supervision, so as to realize the full and fine food safety management [19].

\section{Food SAFETy Problems IN ChINA AND Their CAUSeS}

\section{A. Food safety problems in China}

Problems of food safety have increased in developed and developing countries. Hazards associated with the consumption of food can be classified into sources of risk, namely, microbiological, chemical and technological hazards [14]. The level of public trust in actors in the food chain, such as farmers, manufacturers and retailers, as well as trust in regulatory institutions, may influence the level of consumer confidence in the safety of food in general. Increasing public distrust and reduced consumer confidence in food safety may have adverse economic effects on the food industry, as well as, on an aggregate level, national and international economies. Consumers cannot always judge themselves whether food is safe during the course of normal consumption. As a consequence they have to rely upon others, such as regulators and the food industry, to develop and maintain effective consumer protection activities [6].

In July 2008, reports emerged that several dairy products companies, most notably the Sanlu Group were adulterating milk and infant formula with melamine. A large number of "black workshops" profiteer from selling fake goods, and even some well-known enterprises pursue their own interests at the expense of public interests, such as Sudanhong event, Red Duck egg event, gutter cooking oil incident, the Sanlu milk powder incident and poisonous bean sprouts, tainted pork and leather milk and other major food safety incidents. In recent years, food safety incidents show the following features. First, foods with problem involve not only traditional side-products, but also diary product and fruits, etc. Second, the damage of foods with problem is more and more serious. Third, the ways to produce fake and bad foods vary frequently.

These incidents not only seriously affected the health and safety of consumers, but also caused distress to the country's political stability and economic development, making people's confidence in the government get lower. In this context, strengthening the research on government food safety supervision mechanism is necessary.

\section{B. Main causes of food safety problems}

The factors affect the quality of foods include the original pollution in agriculture, planting industry and breeding industry, microorganism pollution in the process of storing, transporting and processing of materials. Even in the stage of processing, excessive use of food additives and use of illegal additives, misuse of new technology and new craft, all can result in food safety problems. Generally speaking, food safety problems are due to governance failure and market failure. To some extent, above-mentioned phenomena are related to inadequate supervision of government, although there are still some other factors.

Main causes of food safety problems in China come from the following aspects:

\section{1) Production and circulation of foods}

The providers of material, producers of foods and providers of foods pursue economic benefits, lacking in moral consciousness and credit consciousness. They often take dishonest actions for short-term benefits.

\section{2) Asymmetric information}

Consumers with poor information on food safety are very vulnerable, especially the majority of rural residents, urban migrant workers and groups of students, and they are the main victims. Therefore, the behaviors of providers and consumers are important influence factors of food safety issues [16]. Food safety issues arise from problems of asymmetric information which leads to the profit seeking behavior of agents distorting rather than enhancing the creation of one of the four types or marketing utility (time, form, place and possession) [4].

\section{3) Government regulation}

Issues on government regulation are mainly in the following areas: regulatory laws and regulations and technical 
standards are imperfect, government regulation pattern is defective, government regulatory systems are unsound and corresponding inspection methods are backward, regulatory information is poor, and regulatory funding is inadequate. Food safety problems will be more systematically detected.

In this regulatory system, multi-sectoral segment regulatory approach is used. Ministry of Health, Ministry of Agriculture, the State General Administration of Quality Supervision and the Ministry of Commerce respectively supervise one section of food links. On the surface, all departments segmented supervision seems that there are multiple protection mechanisms, but in fact the phenomenon of regulatory overlap and regulatory gaps is serious.

At present, China has not established a comprehensive food safety control system, and the corresponding food safety inspection means is relatively backward, which is reflected in the food safety inspection equipment and inspection technology.

\section{4) Laws and punishment}

China has basically formed the legal framework for food safety, for example, Food Safety Law, as the Basic Law, was supplemented by related regulations, local laws and regulations, and judicial interpretations, and is compatible with other laws. However, there are problems related to low legal effect and light punishment in our food safety law and regulation. In the case of major food safety incidents, the penalties for violations of food safety often take a simple fine or suspend business for rectification, which unable to meet the pedagogical effect [16].

\section{5) Social credit system}

Social credit system is imperfect in China. From the perspective of the whole society, lack of credit and lag of the construction of social credit system compared with the development of market economy are important environmental factors of food safety problems. At present, many countries have established credit record of food safety, so as to track and monitor the situation of food safety. The construction of social credit system in other countries is reflected in strict commitment and recall institutions about the quality of foods. For example, in the United States, if the safety of foods does not match what have promised, the producer has the responsibility to recall them back.

\section{SOME COUNTERMEASURES Against FoOd SAFEty PROBLEMS}

Based on the literatures reviewed and the particular context of China, we put forward some countermeasures against food safety problems. As food safety is a complex system engineering issue and food safety is a multidisciplinary problem requiring new approaches, to solve the problems of food, we should explore measures from different perspectives.

\section{A. Strengthen the supervision of related departments and their coordination}

Food regulation is effective in protecting the health of the public because it works to manage and control food risks through the use of appropriate measures.
The supervision of food safety involves many departments, such as food and drug administration, quality and technical supervision, industry and commerce administration, health and family planning, commerce, agriculture, environment protection, etc. These departments should fulfil their own responsibilities according to the requirement of Food Safety Law and other relevant laws and regulations. On one hand, these departments should strengthen the supervision of all stage, including production and processing, circulation and consumption, and innovate the methods of supervision. On the other hand, they should strengthen coordination, especially in the context of overlap in work.

Chinese Premier Li Keqiang has pointed out, in order to establish a long-term mechanism for food safety, it is necessary to integrate some food safety functions of the members of Food Safety Commission in different levels. Since October 1, 2015, the regulation named three in one, according to a registration code has been implemented in China. Business license issued by bureau of industry and commerce, organization code certificate issued by quality inspection department and tax registration certificate issued by tax department are changed to a single business license, which includes the information about legal person and unified social credit code. In June 2016, general Office of the State Council released the opinion to speed up the reform of "three in one" registration regulation. This reform will play an important role in perfecting social credit system, and have proactive and farreaching effect on the supervision of food safety. At present, many places have finished the "three in one" reform by integrating the functions of bureau of industry and commerce, bureau of quality supervision and food and drug administration. A new bureau of market supervision and administration has been set up, and a system of food and drug administration which integrating administration, supervision and law-enforcing, technology support and serving the first line has been preliminary established.

The global nature of food chain requires national efforts in international context, namely in harmonization of compulsory and voluntary food safety frameworks. The various crises in food safety have led to a reconsideration of the manner in which food safety is managed. The modern structured food safety regulatory systems are increasingly comprehensive but not always more stringent, which is a consequence of the risk assessments nature of modern food law [11].

\section{B. Perfect the system of laws and technical standards}

The government should establish complete laws and regulations system and technology standards, which cover the whole process of food producing, processing and circulating. Meanwhile, the government should increase the investment for introducing or developing advanced supervisory equipments and technologies, improving the monitoring conditions, and providing strong activities to food safety guarantee [16].

Under the background of lighter legal responsibility, the deterrent effect of severe punishment is not obvious, and the situation of food safety is still worse, Food Safety Law is revised and enacted in October 11, 2015. It is regarded as the 
most severe law in food safety in the history. In this law, eight aspects of institutional design guarantee the strictest supervision, six aspects of penalty guarantee severe punishment, four aspects of stipulation guarantee that food safety is governed by the whole society, and three obligations strengthen the supervision of online food transaction.

It's a world-wide tendency to strengthen the legal governance on food safety. In order to cope with legal dysfunction, India promulgated Food Safety and Standard Act 2006. This act built up a unified monitoring system based on science and risk management, and established multiply enforcement system and strengthened legal responsibility, all of which are very helpful to the improvement of India's food safety condition. Because of high cost of its implementation, terrible administrative environment and undeveloped culture of food safety, it hasn't realized its desired goal although it has made some achievements. India's experience enlightened us that China should establish unified monitoring system, strengthen the supervision of the regulators, and perfect the judicial protection [12].

\section{Speed up the construction of credit system of food safety}

In order to resolve food safety issues fundamentally, we should not only improve the government's regulatory mechanisms, develop a sound government regulatory system, and increase the regulatory funding, etc., but also accelerate the construction of food safety credit supervision platform, and strengthen collaboration between government sectors. Song and Tian offered a credit evaluation index system for food enterprise and put forward a framework of food safety credit supervision platform [16]. This platform can enhance communication, and promote coordination and cooperation among various functional sectors. Therefore, it can effectively reduce the phenomenon of regulatory overlap, regulatory gaps and resource waste in the regulatory process, improve regulatory efficiency and the processing speed of emergency, and achieve function and resource synergies of government regulation to some extent.

We should establish and perfect credit management mechanisms such as collecting credit information, sharing credit information and punishing the dishonest behaviors. Food safety credit management should be changed from emphasizing the role of the government and neglecting various participants to relying on the guidance of the government and the governance of the whole society. By this way, we can make full use of credit intermediary organization, media, consumers, and put all kinds of information into credit information system, such as consumer's complaints, media exposure, enterprises' credit evaluation by credit intermediary organization, tax records, environment protection records, price records, and the inspection results of quality sector, etc. Therefore, we can lay a solid foundation for the construction and perfection of social credit system. Moreover, since production, sale and consumption of foods may take place in different areas, food safety credit management is a task covering many regions, it is necessary for all regions to work hard to speed up the construction and perfection of social credit system.

\section{Establish and perfect the mechanism of punishing dishonesty behaviors}

The most important reason why food safety problems often happen despite repeated prohibition is that the government's punishment on dishonest behaviors of food producers and entrepreneurs is light, so the cost of dishonesty behaviors is very low and this will result in their speculation behaviors. Food safety credit management includes not only recording and announcing faithful behaviors, but also punishing the dishonesty behaviors.

Punishing the dishonesty behaviors is the key of food safety credit management. On one hand, bad credit record should be recorded and open to the public. This is accomplished by credit files and credit information sharing. On the other hand, economic punishment on the dishonesty should be used. Relevant sectors should explore punishing mechanism against dishonesty of food producers and entrepreneurs. Especially we should use aggravated punishment, so as to increase dishonesty cost of food producers and entrepreneurs.

\section{CONCLUSIONS}

In the past decades, food safety has become a sensitive and global issue. China's food safety is a serious issue and major fatal food safety incidents occur occasionally. The reasons include the imperfectness of laws, regulations and supervisory system, inadequate punishment, inefficient enforcement, and so on.

In this paper, some countermeasures and recommendations are given, mainly concerning the respects of perfecting the laws, strengthening supervision, accelerating credit system construction and implementing more severe punishment, etc. However, the present study has its limitations, which call for further researches. For example, every suggestion should be expanded and deepen, so as to make it more operational and practical.

\section{ACKNOWLEDGMENT}

This work was supported by the National Natural Science Foundation of China under Grant 71362016, the Scientific Research Foundation of Yunnan Provincial Department of Education under Grant 2012Y125, and the Scientific Research Foundation of Yunnan University of Finance and Economics under Grant YC2012A21.

\section{REFERENCES}

[1] Annabelle M. Wilson, and Samantha B. Meyer, "How food regulators communicate with consumers about food safety, British Food Journal," vol. 117, 2015, pp. 2129-2142.

[2] L.L. Chen, and X. Gao, "Current situation and analysis of food safety supervision in three provinces(city) in China," Chinese Health Resources, vol. 19, 2016, pp. 74-77.

[3] Christopher J. Griffith, "Food safety: where from and where to?" British Food Journal, vol. 108, 2006, pp. 6-15.

[4] David L. Ortega, Colin G. Brown, Scott A. Waldron, and H. Holly Wang, "Agricultural marketing and food safety in China: a utility perspective," Journal of Agribusiness in Developing and Emerging Economies, vol. 4, 2014, pp. 23-31. 
[5] Imca Sampers, and Hajime Toyofuku, "Semi-quantitative study to evaluate the performance of a HACCP-based food safety management system in Japanese milk processing plants," Food Control, 2012, pp. 227-233.

[6] Janneke de Jonge, "Monitoring consumer confidence in food safety: an exploratory study," British Food Journal, vol. 106, 2004, pp. 837-849.

[7] Lena Dzifa Mensah, and Denyse Julien, "Implementation of food safety management systems in the UK," Food Control, 2011, pp. 1216-1225.

[8] P. Liu, and S.J. Zhang, "Toward Regulatory Federalism: A Study on the Vertical Power Distribution of China's Food Safety Regulatory System,' Journal of Huazhong Normal University(Humanities and Social Sciences ,vol. 54, 2015, pp. 28-34

[9] L. Jacxsens, and M. Uyttendaele, "Food safety performance indicators to benchmark food safety output of food safety management systems," International Journal of Food Microbiology, vol. 141, 2010, pp. 180-187.

[10] L. Manning, and R.N. Baines, "Effective management of food safety and quality," British Food Journal, vol. 106, 2004, pp. 598-606.

[11] Nada Smigic, and Andreja Rajkovic, "Legislation, standards and diagnostics as a backbone of food safety assurance in Serbia," British Food Journal, vol. 117, 2015, pp. 94-108.

[12] L.B. Ning, "India's Legal Governance on Food Safety and Its Enlightenment to China," Journal of Political Science and Law, 2015, pp. 129-137.
[13] Photis Papademas, and Thomas Bintsis, "Food safety management systems (FSMS) in the dairy industry: A review," International Journal of Dairy Technology, vol. 63, 2010, pp. 489-503.

[14] M.W. Ruth, and J.M. Yeung, "Food safety risk," British Food Journal, vol. 103, 2001, pp. 170-187.

[15] Sinne Smed, Jørgen Dejgaard Jensen, "Food safety information and food demand," British Food Journal, vol. 107, 2005, pp. 173-186.

[16] G.X. Song, and T. Tian, "Study on China's Food Safety Issues and Supervision Platform Based on Credit Management," Proceedings of 2012 International Conference on Public Management, 2012, pp. 323334.

[17] Y. Yang, and Z.M. Wu, "A comparison of domestic and international food safety supervision mechanism," China Health Law, vo1. 24, 2016, pp. 30-33.

[18] G.X. Zhang, W.X. Gao, and X. Guan, "Evolutionary game model of food safety supervision based on the third-party intendance," Journal of systems Engineering, vol. 30, 2015, pp. 153-164.

[19] Y. Zhao, "Relying on the 'Internet plus' to construct a new mode of food safety supervision,” Economic Research Guide, 2016, pp. 114-116.

[20] Zhelyu Vladimirov, "Implementation of food safety management system in Bulgaria," British Food Journal, vol. 113, 2011, pp. 50-65. 